Supplement of Atmos. Meas. Tech., 13, 3717-3729, 2020

https://doi.org/10.5194/amt-13-3717-2020-supplement

(c) Author(s) 2020. This work is distributed under

the Creative Commons Attribution 4.0 License.

(c) (1)

\author{
Atmospheric \\ Measurement \\ Techniques
}

Supplement of

\title{
MIMiX: a Multipurpose In situ Microreactor system for X-ray microspectroscopy to mimic atmospheric aerosol processing
}

Jan-David Förster et al.

Correspondence to: Jan-David Förster (jd.forster@mpic.de) and Christopher Pöhlker (c.pohlker@mpic.de)

The copyright of individual parts of the supplement might differ from the CC BY 4.0 License. 


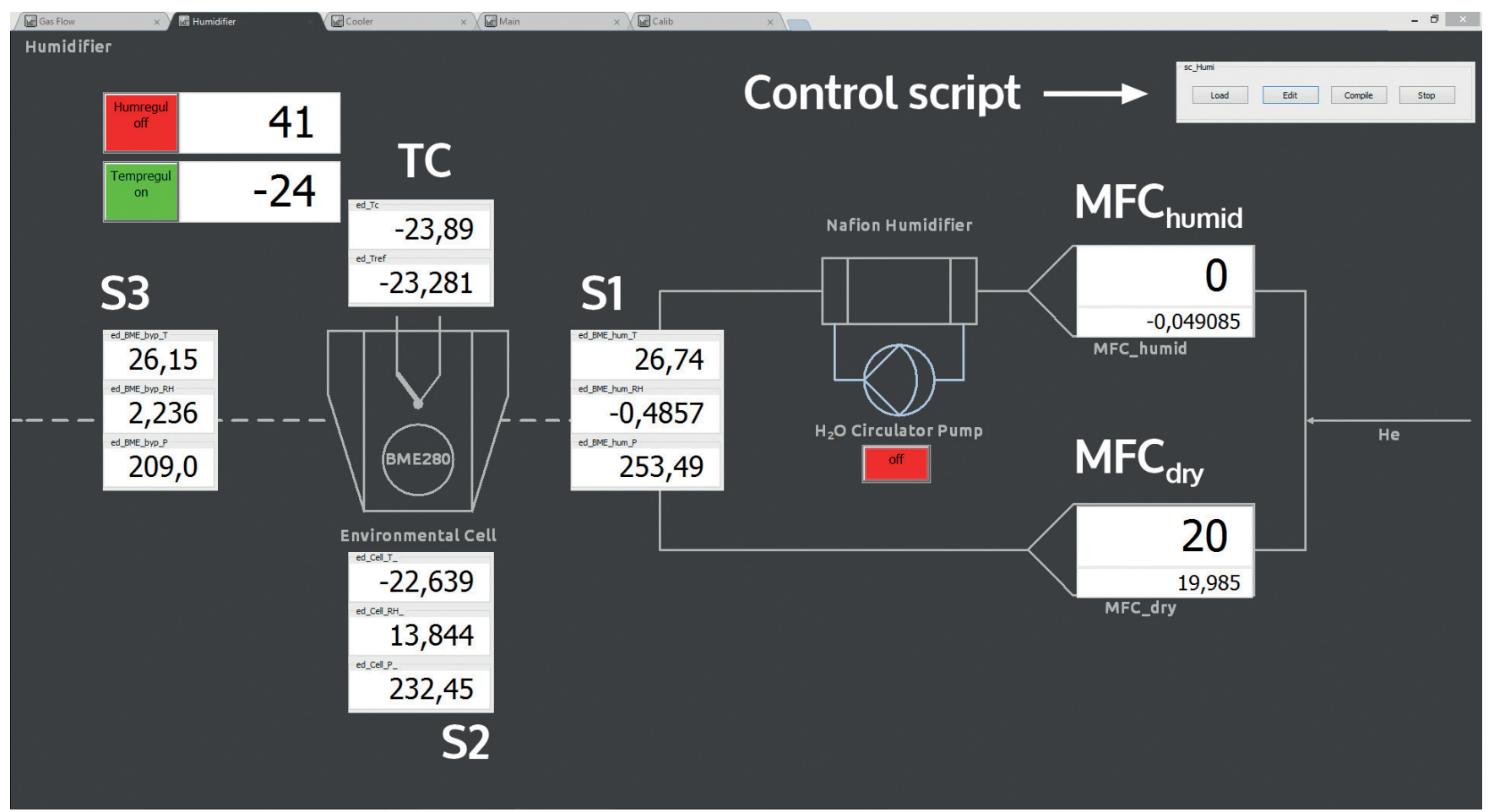

Figure S1. Screenshot of the T and RH control panel in the graphical user interface, emphasizing the cooling capacities of the setup. Please note that the sensor values here, are uncalibrated. The actual microreactor temperature is at about $250 \mathrm{~K}$. 


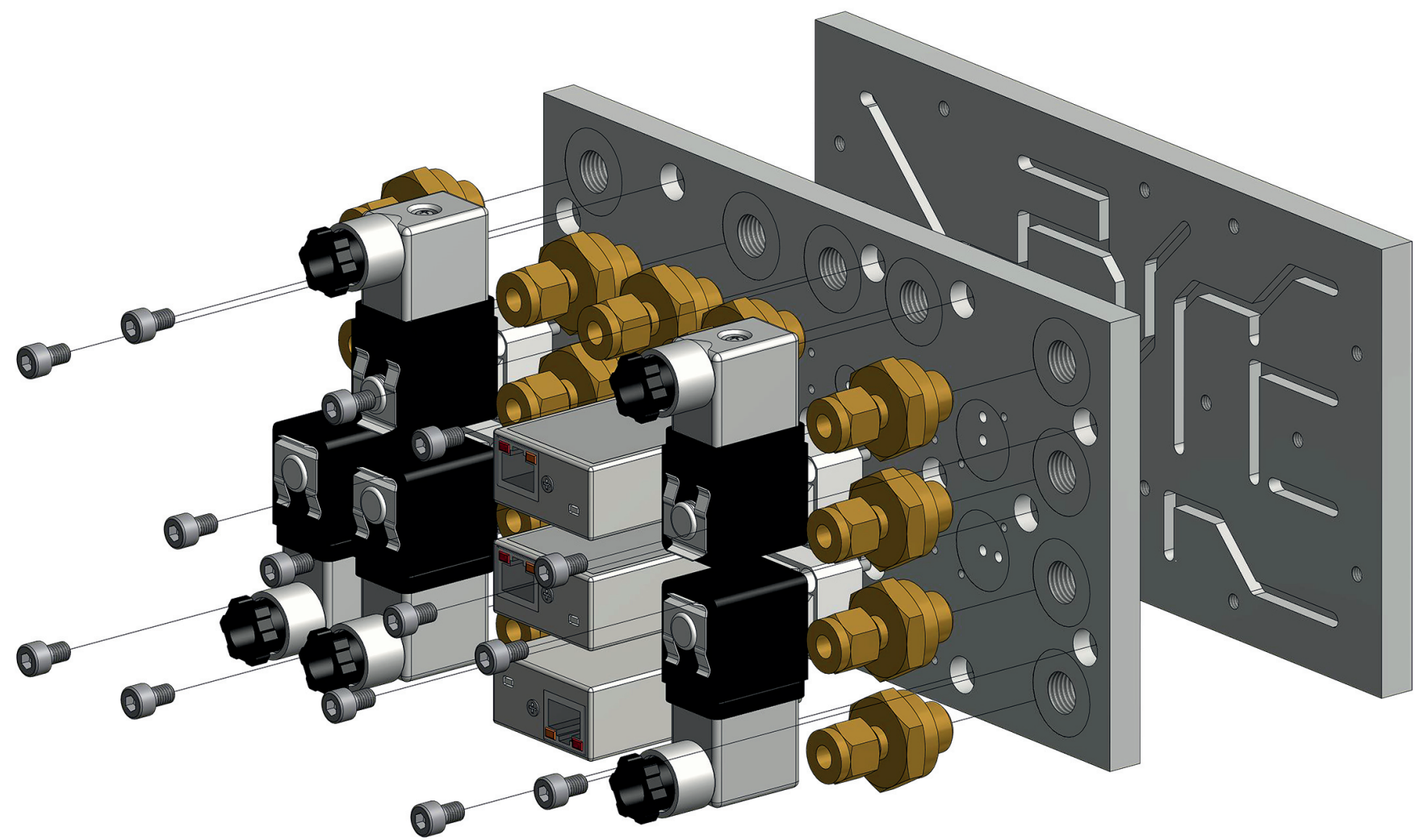

Figure S2. Exploded view of the gas flow circuit board, showing solenoid shut off valves, mass flow controllers, and the pressure controller. The screwed-in brass metal connectors serve two purposes: i) they connect the external gas supply to the circuit, the humidifier and eventually to the external pump; ii) they act as sockets for the environmental sensors and therefore allows for their quick replacement in case of a failure.
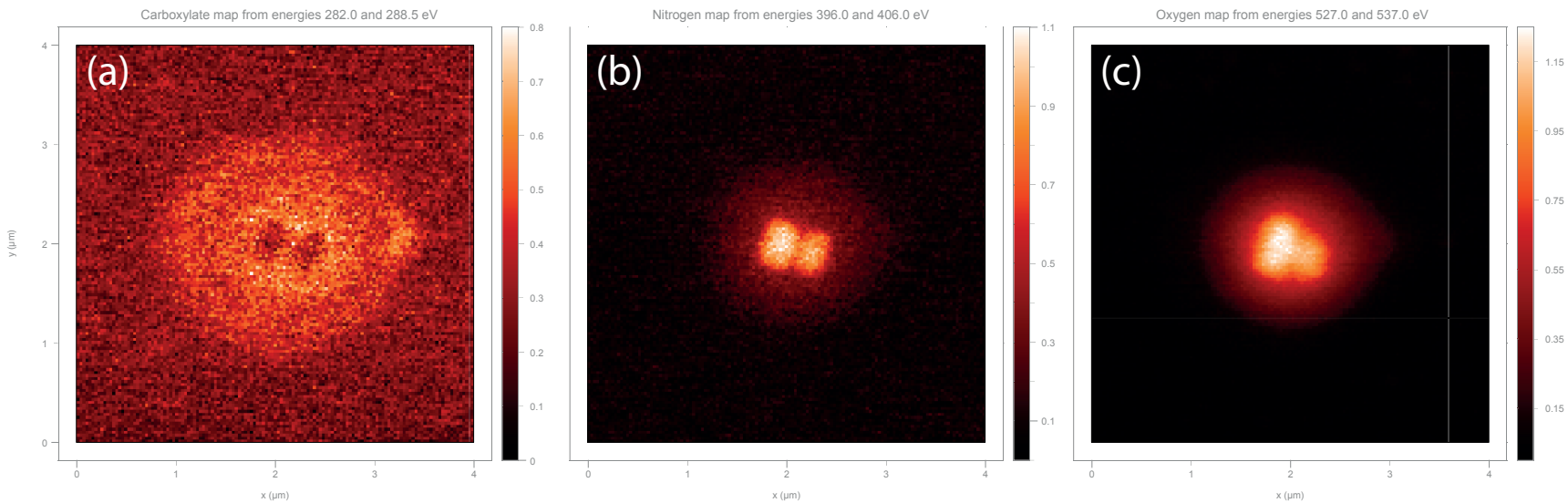

Figure S3. Carbonaceous contamination on ammonium sulfate particles at 65\% RH using "KaWeS - Joint grease without silicon" as lubricant. a) Carboxylate map from energies 282.0 and $288.5 \mathrm{eV}$; b) Nitrogen map from energies 396.0 and $406.0 \mathrm{eV}$; c) Oxygen map from energies 527.0 and $537.0 \mathrm{eV}$ 